\title{
ANALYSIS OF RAFT FOUNDATION USING FINITE ELEMENT APPROACH
}

\author{
Miss. Swati Dlilip Limkar ${ }^{1}$, Dr. M.G.Kalyanshetti ${ }^{2}$ and Dr.S.A.Halkude ${ }^{3}$
}

\begin{abstract}
Normally, a structure resting on soil having low bearing capacity and where differential settlement due to erratic nature of soil is expected, raft foundation is recommended to cope-up with mixed or poor ground condition and simultaneously to transfer heavy loads to ground while controlling the differential settlement. The essential task in the analysis of a raft foundation is the determination of the distribution of contact pressure underneath the raft which is a complex function of the rigidity of the superstructure, raft itself and supporting soil .The IS : 2950 (Part I )-1981 recommends the analysis based on the assumption of liner distribution of contact pressure. However due to complex / erratic nature of soil \& flexibility of the raft, this assumption is away from reality, which will leads to erroneous results. Therefore in order to ensure precision in the analysis and to simulate the realistic condition of interface of soil mass and raft, a discretization of raft is done using finite element method and springs are used below the node points to realistically simulate the soil flexibility. The application software (SAFE 2000) is used for finite element analysis. In this study the attempt is made to evaluate the effectiveness of finite element approach by studying moments along $\mathrm{x}$ direction, moment along $\mathrm{y}$ direction and soil pressure beneath the raft. This study is carried out on three types of soil; loose, medium and hard soil. Study reveals that finite element formulation minimizes the error to the significant extent in the results due to correction in assumption of liner pressure distribution. Study also reveals that finite element approach is found effective in case of loose and medium soil as error is magnified due to the assumption of liner pressure distribution in conventional approach.
\end{abstract}

Keywords - Rigid raft Foundation, Safe bearing capacity of soil, Conventional approach, Finite element approach, Deflection, Moment, Soil pressure, Soil modulus of elasticity.

\section{INTRODUCTION}

A raft is a combined footing that covers the entire area beneath a structure and supports all the walls and columns. When allowable soil pressure is low, or the building loads are heavy, the use of spread footing would cover more than one-half of the area and it may prove more economical to use raft foundation. They are also used where the soil mass contains compressible layers or the soil is sufficiently erratic so that the differential settlement would be a challenge to control. The raft tends to bridge over the erratic deposits and eliminates the differential settlement. Raft foundation is used to reduce settlement above highly compressible soil, by making the weight of the structure and raft approximately equal to the weight of the soil excavated.

The essential task in the analysis of a raft foundation is the determination of the distribution of contact pressure underneath the raft which is a complex function of the rigidity of the superstructure, raft and supporting soil. This necessitates a number of simplifying assumptions to make the problem open to analysis. Once the distribution of contact pressure is determined, bending moments and shear force can be computed based on statics. IS: 2950 (PartI)1981 recommends few methods of analysis based on certain assumptions.

\footnotetext{
${ }^{1}$ P.G.Studant Walchand Institute of Technology, Solapur, Maharashtra, India

${ }^{2}$ Assistant professor, Department of Civil Engineering Walchand Institute of Technology, Solapur, Maharashtra, India

${ }^{3}$ Principal Walchand Institute of Technology, Solapur, Maharashtra, India
} 
Many researchers have proposed that the behavior of raft foundation can be studied by using finite element approach. Dr.Shihada et al. ${ }^{[1]}$ (2008), compared results from analysis using the conventional approach and the Finite element approach (SAP2000 software). They concluded that moment value obtained from conventional method is more than the finite element method. Dr. Mohammed Al-Ansari ${ }^{[2]}$ (2009), studied the design of raft foundation in loose sand and found that using software results are more accurate. Mohamed Saad El din et al. ${ }^{[3]}$ (2014), analysed raft foundation using PLAXIS programme to study the effect of opening position and different types of soil. They found that opening and type of soil have important effect on settlement of soil and moment of raft foundation. Dr.S.A.Halkude et al. ${ }^{[4]}$ (2014), carried out dynamic analysis using response spectra. The soil flexibility is incorporated in the analysis using spring model for incorporating soil flexibility and FEM model for diserization of raft. They found that SSI significantly affects the response of the structure; FEM is effective approach for consideration of elastic continuum beneath foundation. Dr.S.S.Patil et al. ${ }^{[5]}$ (2016), carried out the effect of soil flexibility on the performance of the building frame resting on raft foundation. They found that base shear increases due to SSI effect. The effect of SSI increases and tends to become prominent with increasing softness of the soil.

In the present study analysis of raft foundation for a 'G+7 Story' building situated in Earthquake Zone-3 is carried out for all load combinations in accordance with IS: 875-2002(Part-V). The study focuses on the evaluation of various flexural parameters such as moment along $\mathrm{x}$, $\mathrm{y}$ direction and soil pressure beneath raft and comparison of result obtained by conventional method and finite element method. In present study springs are used to incorporate soil flexibility in place of linear variation of soil pressure beneath raft considered in conventional method. This study is carried out on three types of soil; loose, medium and hard soil.

\section{II.FORMULATION}

The analysis of raft with the conventional approach of assuming uniform soil pressure beneath the raft is discussed in following section with the help of typical building plan as shown in Figure 1 (a).

The conventional analysis is based on the assumption that foundation is rigid relative to the supporting soil and the compressible soil layer is relatively shallow. The geometry of the raft consider such that, the contact pressure variation is assumed as planar, such that the centroid of the contact pressure coincides with the line of action of the resultant force of all loads acting on the foundation.The procedure for the conventional approach consists of considering column strip beneath footing as shown in Figure 1 (a).The pressure distribution below footing is considered linearly varying as shown in Figure 1 (b).

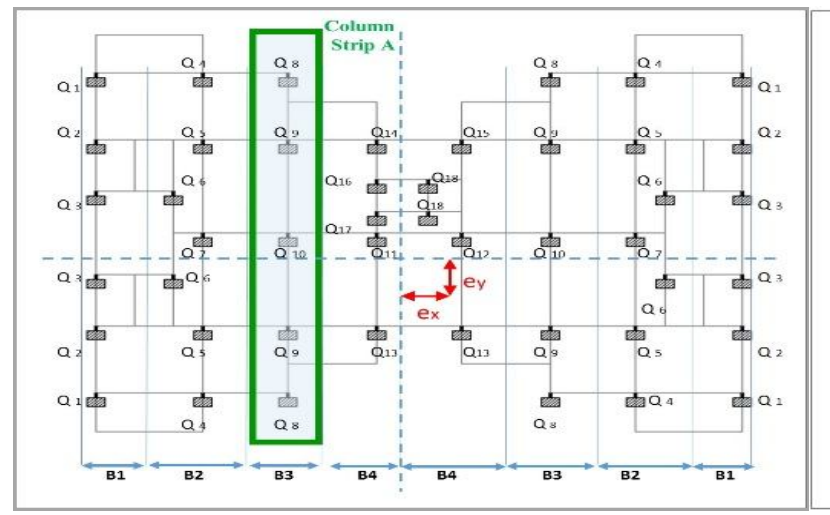

(a)

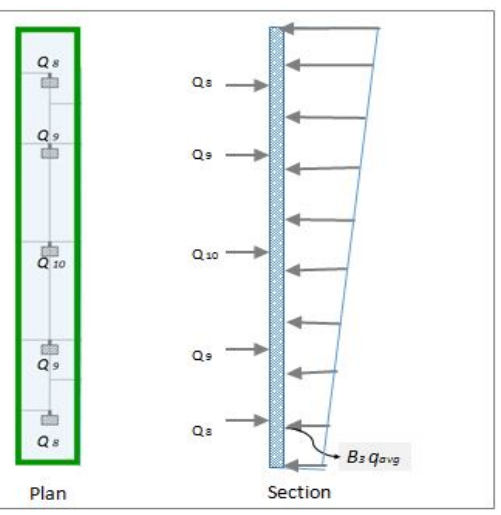

(b)

Figure 1. (a) Plan of Raft Foundation (b) Plan and section of column strip

In order to derive more preciseness raft footing is analyzed using finite element method. The raft is idealized as a mesh of finite elements interconnected only at the nodes (corners), and the soil is modeled as a set of isolated springs (Winkler foundation).

\section{PARAMETRIC STUDY}

A case study of 7-storyed residential building located in zone III is analyzed and studied using structural design software (STAAD). See Figure 3 (a) for dimensions and geometry. Parameters are considered in STAAD are 
mentioned in Table 1. Different loads i.e. Dead Load, Live Load, and Earthquake load are calculated according to respective Indian Standard Codes (I.S.456 - 2002). All the loads are calculated as per as I.S.875 (Part I \& Part II) and 1893 (Part III).The loads on 18 column are obtained from worst load combination i.e. (Dead Load + Live Load) $\mathrm{x}$ 1.5. These are used in analysis of raft foundation.

\begin{tabular}{|l|l|}
\hline \multicolumn{2}{|c|}{ Table -1 Input Data in STAAD } \\
\hline Parameters & Input Data for STAAD \\
\hline Type of Building & Residential $(\mathbf{G + 7})$ \\
\hline Plan Dimension $(\mathbf{m})$ & $\mathbf{2 3 . 0 6} \times 15.18$ \\
\hline Total Height of Building $(\mathbf{m})$ & $\mathbf{2 5 . 2 0}$ \\
\hline Floor to floor height $(\mathbf{m})$ & $\mathbf{3 . 0}$ \\
\hline Column Size $(\mathbf{m m})$ & $\mathbf{2 3 0 \times 7 5 0}$ \\
\hline Beam Size $(\mathbf{m m})$ & $\mathbf{2 3 0} \times 600,230 \times 450$ \\
\hline Slab Thickness $(\mathbf{m m})$ & $\mathbf{1 5 0}$ \\
\hline
\end{tabular}

In the present study, analysis of raft is done using column strip A, B and C as shown in Figure 2. Along strip A the columns are heavily loaded and also spacing between the columns is more along $\mathrm{Y}$ direction, which will lead to higher bending moments in $\mathrm{Y}$ direction. Therefore, column strip A is considered for evaluation of bending moment along Y direction.

Similarly, along column Strip C the columns are heavily loaded and also spacing between the columns is more in $\mathrm{X}$ direction, which will lead to higher bending moments in $\mathrm{X}$ direction. Therefore column strip $\mathrm{C}$ is considered for evaluation of bending moment along $\mathrm{X}$ direction.

For soil Pressure column strip B is considered, wherein maximum pressure is expected due to heavy load on the columns along $\mathrm{X}$ direction as compared to $\mathrm{Y}$ direction.

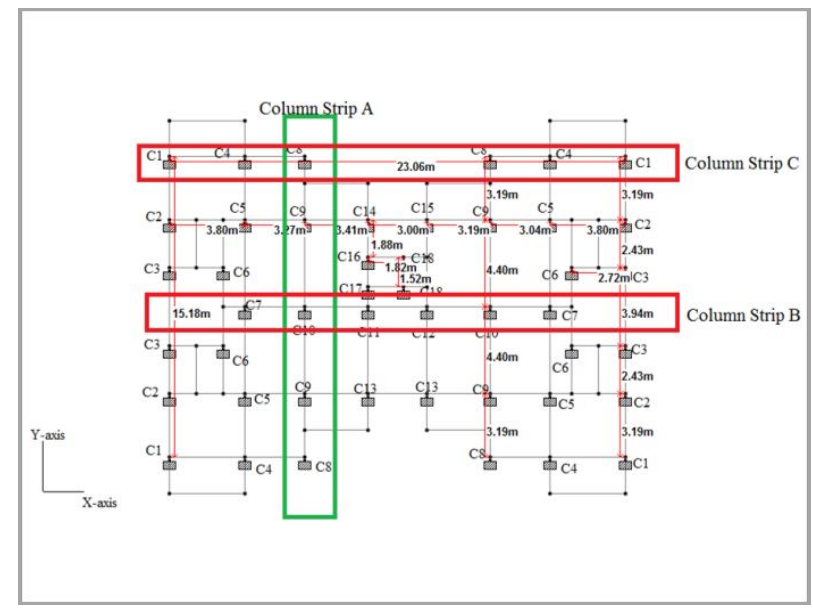

Figure 2. Building plan with column strip

The raft is modeled in SAFE software. The convergence is carried out to eliminate error due to mesh size. Element sizes from $1 \mathrm{~m} \times 1 \mathrm{~m}$ to $0.1125 \mathrm{~m} \times 0.1125 \mathrm{~m}$ are considered with decrement of $0.1 \mathrm{~m}$ in size in either direction. Based upon convergence study it is observed that, the mesh size $0.1125 \mathrm{~m} \times 0.1125 \mathrm{~m}$ yields the converged results and they are opted for further parametric study. The meshing is shown in Figure 3 (b). Moment and deflection are the parameters considered for convergence study. These are indicated in Graph 1 (a) and (b).Convergence study is carried out for column strips A, B and C as shown in Figure 2.The study is carried out for computation of moment in $\mathrm{x}$ direction, moment in $\mathrm{y}$ direction and soil pressure beneath raft. 


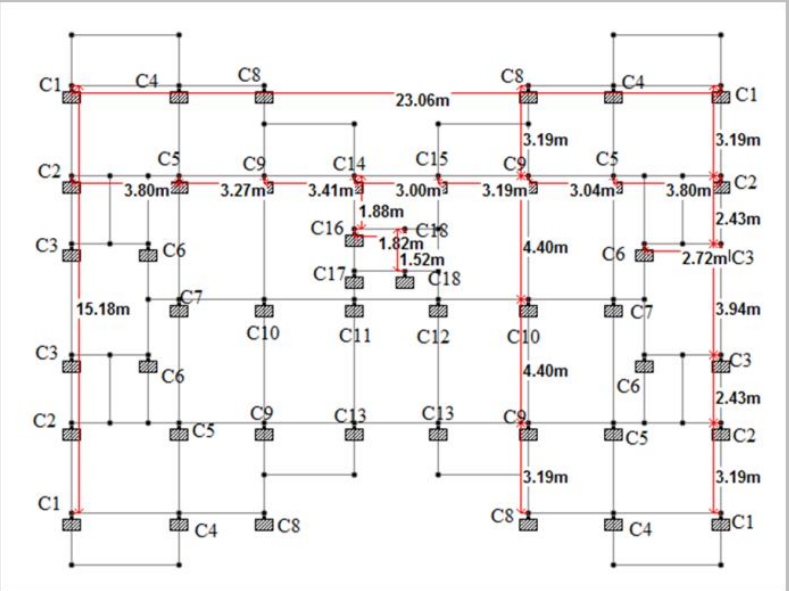

(a)

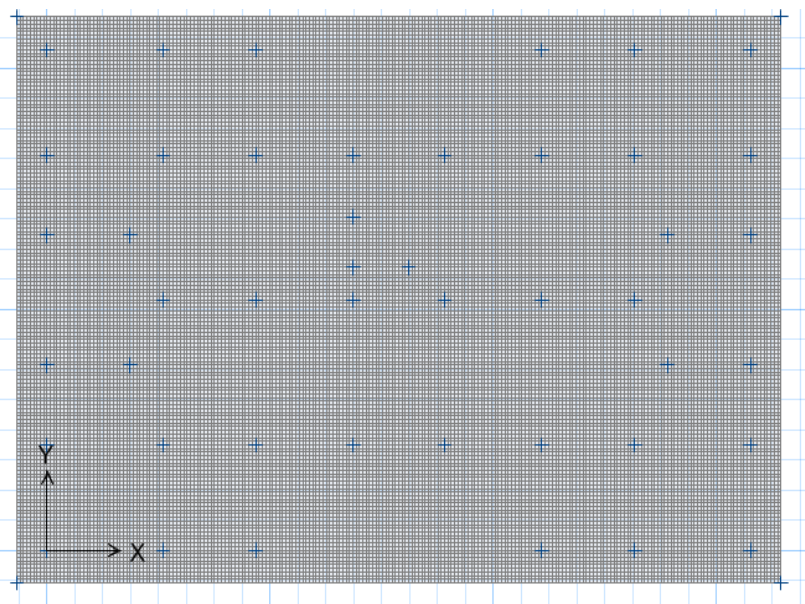

(b)

Figure 3. (a) Building Plan with column numbers (b) Mesh size $0.1125 \mathrm{~m}$ x $0.1125 \mathrm{~m}$

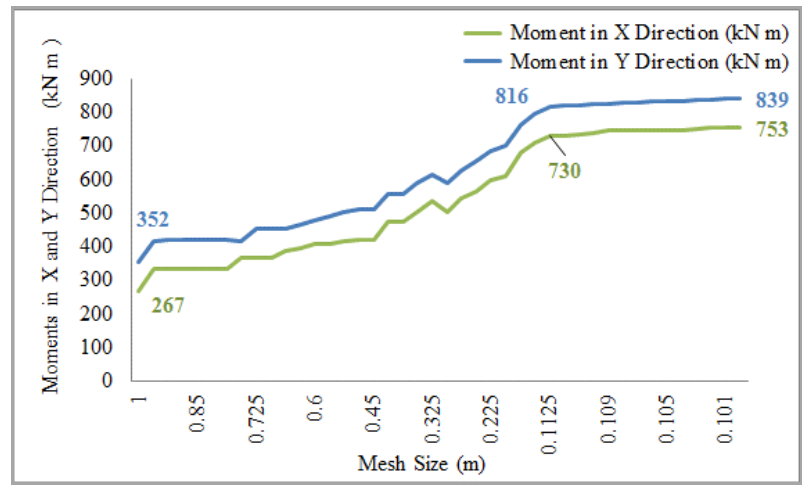

(a)

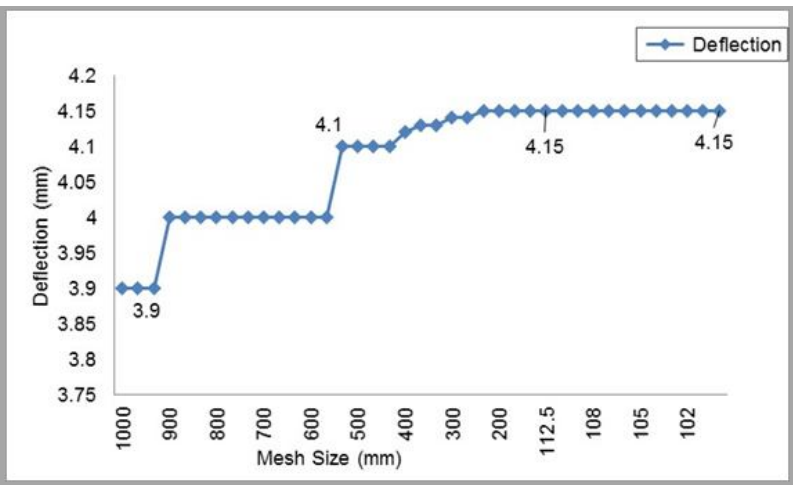

(b)

Graph 1. Convergence study for variation of mesh size (a) Moments (b) Deflection

Further study is carried out for the comparison of conventional approach and finite element approach. Study is carried out on three types of soil namely loose, medium and hard soil. The design parameters used for study is shown in Table 2.

\begin{tabular}{|c|c|c|c|}
\hline Parameters considered & Case 1 & Case 2 & Case 3 \\
\hline Soil Type & Loose & Medium & Hard \\
\hline S.P.T value (As per IS:2950-Part I-1981) & $<5$ & 25 & 40 \\
\hline S.B.C $\left(\mathbf{k N} / \mathbf{m}^{2}\right)$ & 100 & 250 & 1000 \\
\hline $\begin{array}{l}\text { Maximum Permissible Settlement(mm) } \\
\text { (As per IS:2950-Part I-1981 ) }\end{array}$ & 75 & $\mathbf{5 0}$ & 25 \\
\hline Soil Modulus of elasticity (kN / m²) (Bowles) & 1333 & 5000 & 40000 \\
\hline Depth of Raft (mm) & 1500 & 1000 & 850 \\
\hline Area of Raft Foundation ( $L$ x B ) & $28 \times 21$ & $26.06 \times 18.18$ & $25.06 \times 17.18$ \\
\hline Compressive Strength of Concrete Fck $\left(\mathrm{N} / \mathrm{mm}^{2}\right)$ & 30 & 30 & 30 \\
\hline Maximum Load Combination & (1.5) D.L+L .L & (1.5) D.L+L .L & (1.5) D.L+L .L \\
\hline
\end{tabular}




\section{RESULT AND DISCUSSION}

After the analysis of raft by using conventional approach and finite element approach, Moment and soil pressure were studied \& compared with the help of graphs presented below. It is pertinent to note that the raft considered has geometrical symmetry about either axes, however not perfectly symmetrical loading wise.

\section{A. Moment in X Direction (Column strip C)}

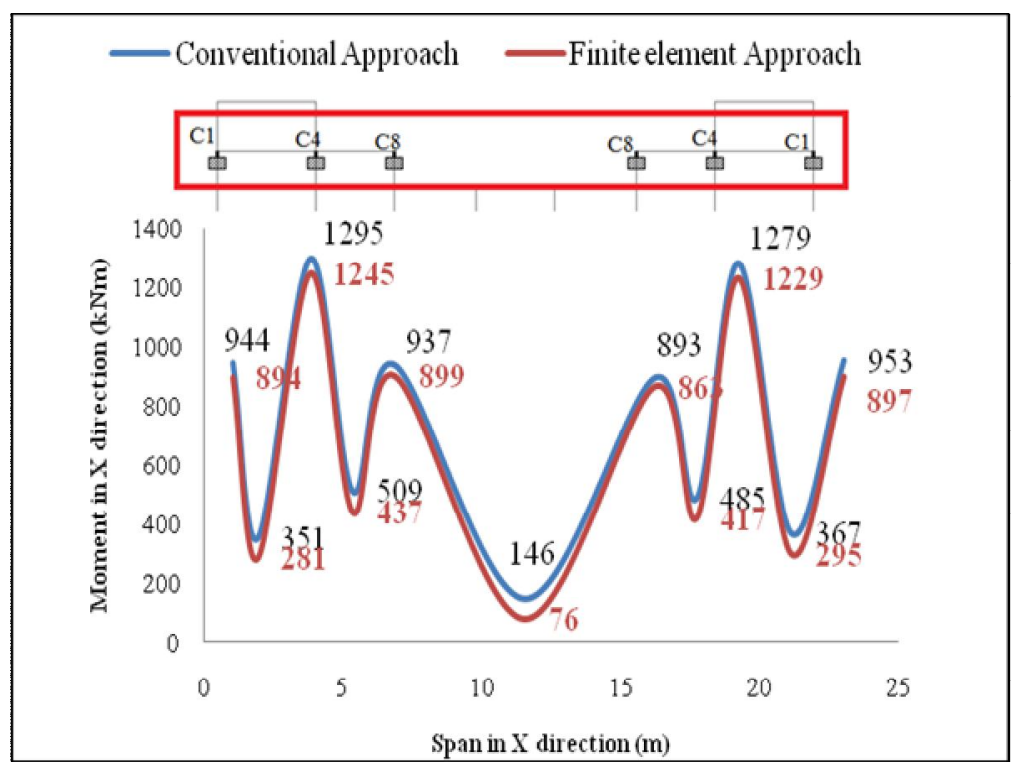

Graph 2.Variation of Moment in X direction (column strip C) for loose soil.

Graph 2 shows variation of moment in X direction for loose soil along column strip C (Refer Figure 2). As per as conventional approach, at column C1 a sagging bending moment is $944 \mathrm{kNm}$.In between column C1 and C4, bending moment decrease from $944 \mathrm{kNm}$ to $351 \mathrm{kNm}$, which further increases and becomes $1295 \mathrm{kNm}$ under column C4. Further bending moment decreases from $1295 \mathrm{kNm}$ to $509 \mathrm{kNm}$ at in between $\mathrm{C} 4$ and C8.Then the bending moment increase from $509 \mathrm{kNm}$ to $937 \mathrm{kNm}$ at under column C8. The bending moment decrease to a minimum sagging value of $146 \mathrm{kNm}$ at a center of strip C. Same trend of bending moment is observed on other half of the column strip. Therefore it can be seen that the bending moment beneath column location is higher in comparison with in between the column. Moreover bending moment beneath edge column is lower and for first intermediate column it increases, which goes on reducing towards the center of the column strip. However it is also observed that along the entire column strip the bending moment is sagging in nature.

Variation of bending moment for the same strip (column strip C), is also studied by finite element approach. It is observed that bending moment obtained by finite element approach is lesser as compared to the conventional approach. The finite element approach gives $281 \mathrm{kNm}$ between $\mathrm{C} 1$ and $\mathrm{C} 4$ which is lower by $25 \%$ in comparison with conventional approach. Under column C4; bending moment obtained by finite element approach is lower by 4 $\%$ in comparison with conventional approach. At center of $\mathrm{C} 4$ and $\mathrm{C} 8$, finite element approach $437 \mathrm{kNm}$ (16.4\% lower than conventional approach). Under column C8, finite element computes $899 \mathrm{kNm}$ which is $4.2 \%$ lower than conventional approach. In between two columns C8, bending moment is $92 \%$ lower than conventional approach. Overall finite element approach computes bending moment in $\mathrm{X}$ direction which is lower in comparison with conventional method, generally in range of $4 \%$ to $92 \%$.

A typical stress contour of raft for loose soil using finite element approach is shown in Figure 4. 


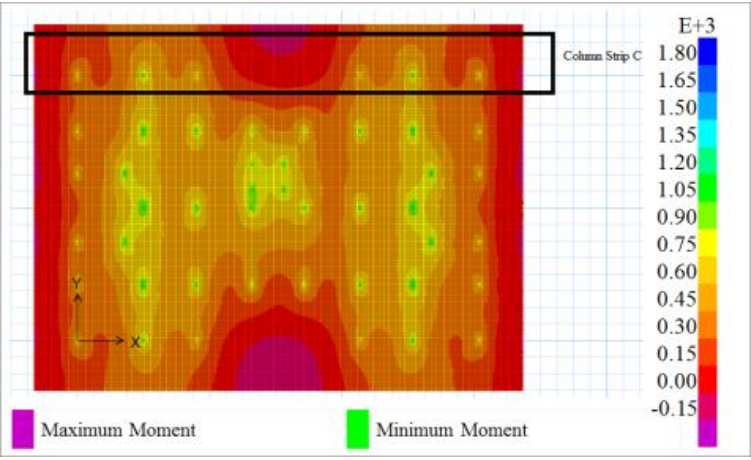

Figure 4 .Contour diagram of moment in $\mathrm{X}$ direction for loose soil

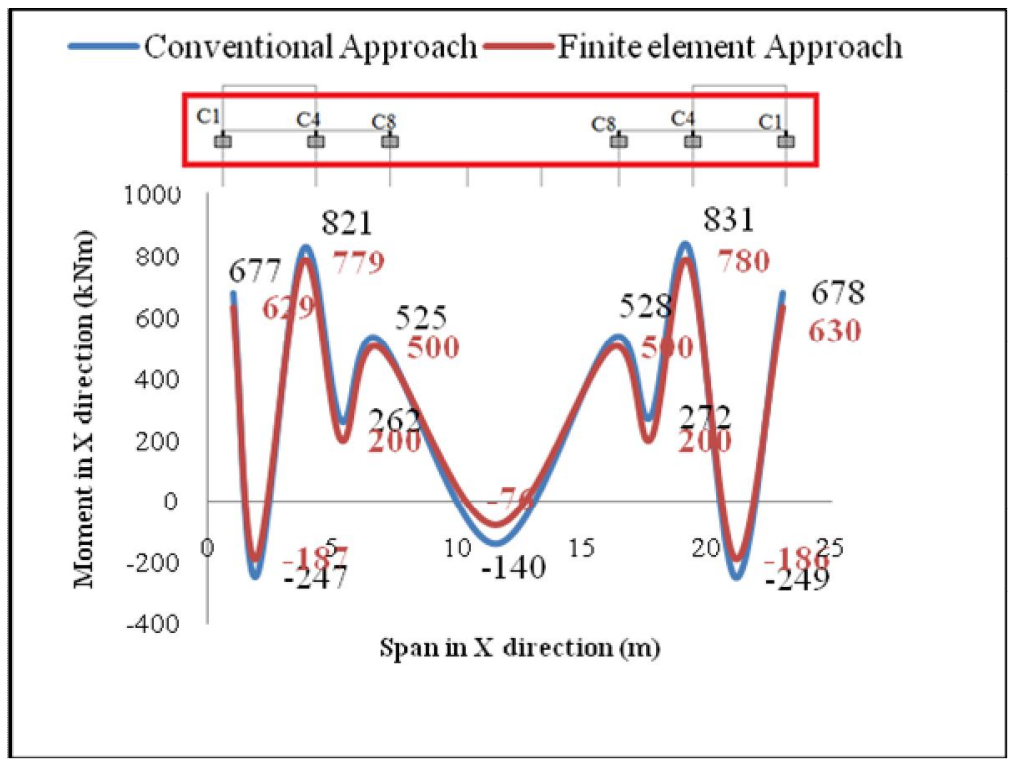

Graph 3.Variation of Moment in X direction (column strip C) for medium soil.

Graph 3 shows variation of moment in X direction for medium soil along column strip C (Refer Figure 2).As per as conventional approach, at column $\mathrm{C} 1$ a sagging bending moment of $677 \mathrm{kNm}$. In between column $\mathrm{C} 1$ and $\mathrm{C} 4$, bending moment decrease from $677 \mathrm{kNm}$ (sagging) to $247 \mathrm{kNm}$ (hogging), this further increases and becomes 821 $\mathrm{kNm}$ (sagging) under column C4. Further bending moment decreases $821 \mathrm{kNm}$ (sagging) to $262 \mathrm{kNm}$ (sagging ) at in between $\mathrm{C} 4$ and $\mathrm{C} 8$. Then the bending moment increase from $262 \mathrm{kNm}$ (sagging) to $525 \mathrm{kNm}$ (sagging) at under column C8.The bending moment decrease to minimum hogging $140 \mathrm{kNm}$ at a center of strip C. Same trend of bending moment is presented for the remaining half of the column strip. It is observed that sagging bending moment is observed at column location and hogging bending moment is observed at middle panel.

Variation of bending moment for the same strip (column strip C), it studied by finite element approach. It is observed that bending moment obtained by finite element approach is lesser as compared to the conventional approach. The finite element approach gives $187 \mathrm{kNm}$ between $\mathrm{C} 1$ and $\mathrm{C} 4$ which is lower by $32 \%$ in comparison with conventional approach .Under column $\mathrm{C} 4$; bending moment obtained by finite element approach is lower by $5.4 \%$ in comparison with conventional approach. At center of $\mathrm{C} 4$ and C8, finite element approach $200 \mathrm{kNm}(31 \%$ lower than conventional approach). Under column $\mathrm{C} 8$, finite element computes $500 \mathrm{kNm}$ which is $5 \%$ lower than conventional approach. In between two columns $\mathrm{C} 8$, bending moment is $84 \%$ lower than conventional approach. Overall finite element approach computes its bending moment in X direction which is lower generally in range of $5 \%$ to $84 \%$. 
In both the approaches, between edge and first intermediate column it is observed that a tension zone is developed indicating raft leaving contact with the sub soil. Also at the center of column strip tension zone is observed. However the intensity of tension developed at the center of the raft is of lower in comparison with those tension zone developed near the edge.

A typical stress contour of raft for medium soil using finite element approach is as shown above in Figure 5.

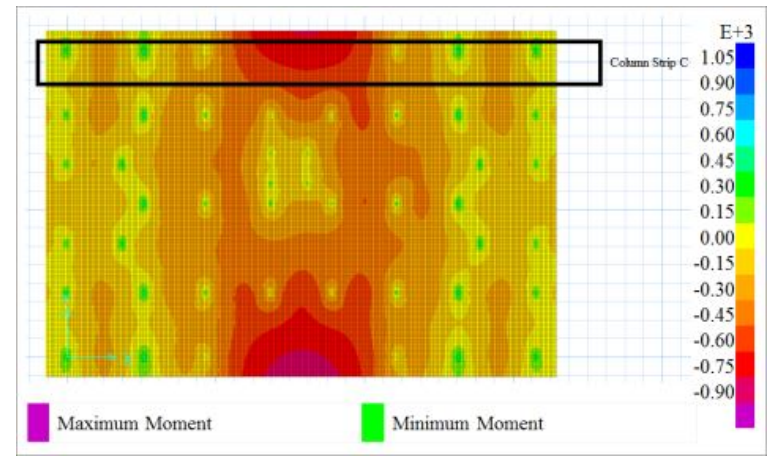

Figure 5. Contour diagram of moment in $\mathrm{x}$ direction for medium soil

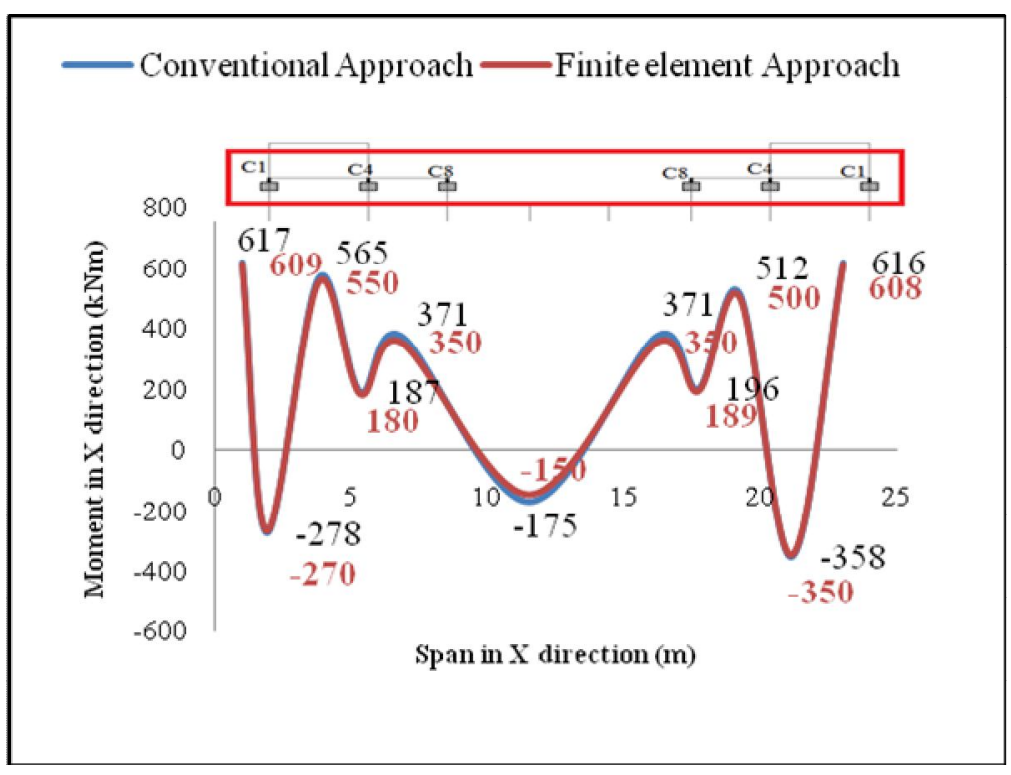

Graph 4.Variation of Moment in X direction (column strip C) for hard soil.

Graph 4 shows variation of moment in X direction for hard soil along column strip C (Refer Figure 2). As per as conventional approach, at column $\mathrm{C} 1$ a sagging bending moment of $617 \mathrm{kNm}$. In between column $\mathrm{C} 1$ and $\mathrm{C} 4$, bending moment decrease from $617 \mathrm{kNm}$ (sagging) to $278 \mathrm{kNm}$ (hogging), this further increase and become 565 $\mathrm{kNm}$ (sagging) under column C4. Further bending moment decreases $565 \mathrm{kNm}$ (sagging) to 187 (sagging) $\mathrm{kNm}$ at in between $\mathrm{C} 4$ and $\mathrm{C} 8$. Then the bending moment increase from $187 \mathrm{kNm}$ (sagging) to 371 (sagging) $\mathrm{kNm}$ at under column C8.The bending moment decrease to a minimum hogging $175 \mathrm{kNm}$ at a center of strip C. Same trend of bending moment is presented for the remaining half of the column strip. It is observed that sagging bending moment is present at column location and hogging bending moment is present at middle panel.

Variation of bending moment for the same strip (column strip C), it studied by finite element approach. It is observed that bending moment obtained by finite element approach is lesser as compared to conventional approach. The finite element approach gives $270 \mathrm{kNm}$ at location of center of $\mathrm{C} 1$ and $\mathrm{C} 4$ which is lower by $3 \%$ in comparison with conventional approach. Under column C4, bending moment obtained by finite element approach is lower by 
$2.7 \%$ in comparison with conventional approach. At center of $\mathrm{C} 4$ and C8, finite element approach $180 \mathrm{kNm}(3.8 \%$ lower than conventional approach). Under column C8, finite element computes $350 \mathrm{kNm}$, which is $6 \%$ lower than conventional approach. In between two columns C8, bending moment is $16.7 \%$ lower than conventional approach. Overall finite element approach computes its bending moment in $\mathrm{X}$ direction which is lower generally in range of $2.7 \%$ to $16.7 \%$.

Between edge and first intermediate column it is observed that a tension zone is developed indicating raft leaving contact with the sub soil. Also, at the center of column strip tension zone is observed. However the intensity of tension developed at the center of the raft is higher intensity in comparison with medium soil.

Considering the variation of bending moment in $\mathrm{X}$ direction for all type of soil, same trend is observed for all type of soil. It is observed that, in case of loose soil the bending moment remains sagging in nature along entire column strip. With increasing stiffness of soil, tension zone are getting developed. As the stiffness of the soil increases it is observed that as one travels from edge towards center, the intensity of bending moment in tension zone increases. The extent of influence of tension zone increases as well. A typical stress contour of raft for hard soil using finite element approach is shown in Figure 6.

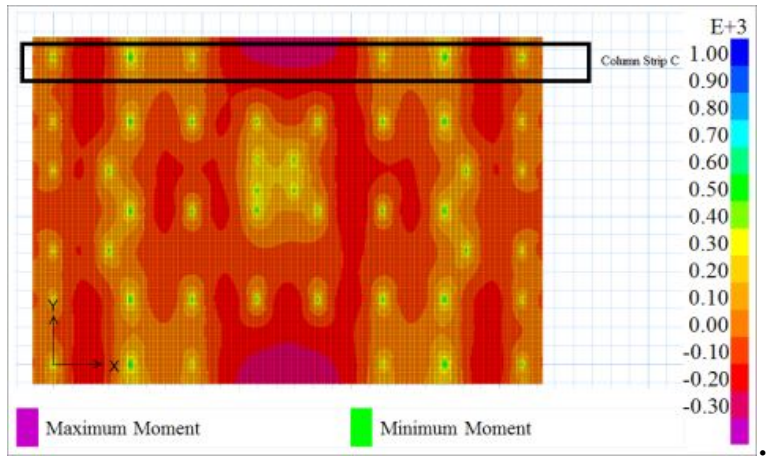

Figure 6. Contour diagram of moment in X direction for hard soil

B. Moment in Y Direction (Column strip A)

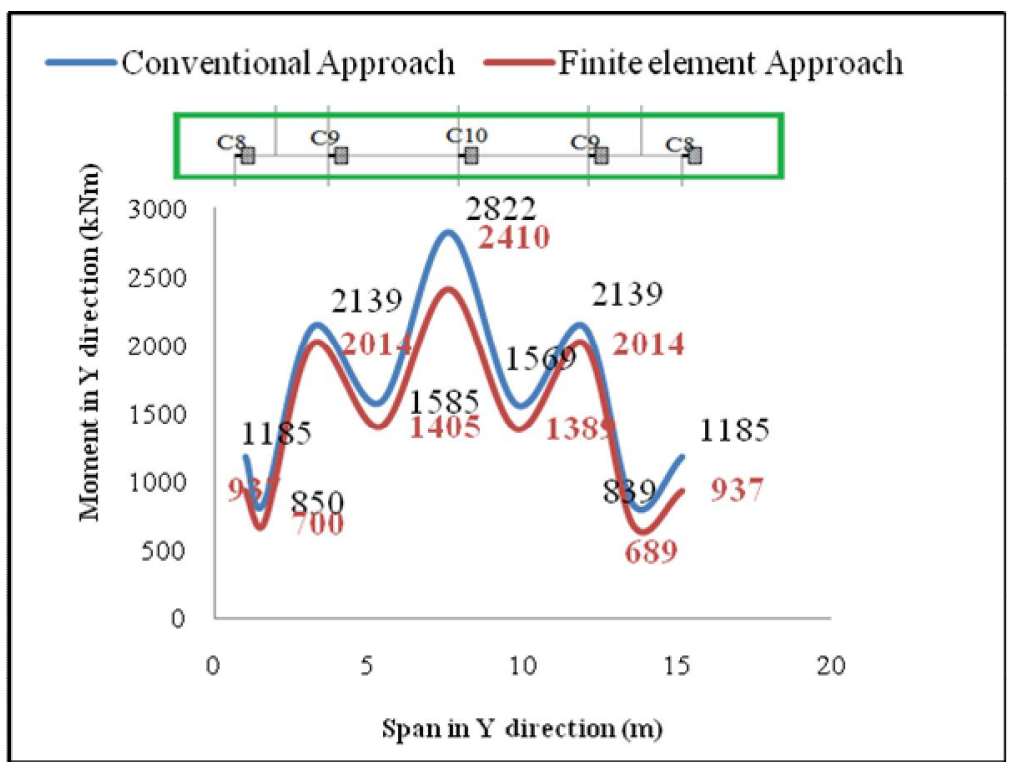

Graph 5.Variation of Moment in Y direction (column strip A) for loose soil. 
Graph 5 shows variation of moment in $\mathrm{Y}$ direction for loose soil along column strip A (Refer Figure 2). As per conventional approach, at column C8 a sagging bending moment of $1185 \mathrm{kNm}$. In between column C8 and C9, bending moment decrease from $1185 \mathrm{kNm}$ to $850 \mathrm{kNm}$, this is a further increase and becomes $2139 \mathrm{kNm}$ under column C9. Further bending moment decreases $2139 \mathrm{kNm}$ to $1585 \mathrm{kNm}$ at in between C9 and C10.Then the bending moment increase from $1585 \mathrm{kNm}$ to $2822 \mathrm{kNm}$ at under column C10. Same trend of bending moment is observed on other half of the column strip. Therefore it can be seen that the bending moment beneath column location is higher in comparison with in between the column. Moreover bending moment beneath edge column is lower and for first intermediate column it increases, which goes on increase towards the center of the column strip. However it is also observed that along the entire column strip the bending moment is sagging in nature.

Variation of bending moment for the same strip (column strip A), is also studied by finite element approach. It is observed that bending moment obtained by finite element approach is lesser as compared to conventional approach. The finite element approach gives $850 \mathrm{kNm}$ between $\mathrm{C} 8$ and $\mathrm{C} 9$ which is lower by $21.4 \%$ in comparison with conventional approach. Under column C9; bending moment obtained by finite element approach is lower by $6.2 \%$ in comparison with conventional approach. At center of $\mathrm{C} 9$ and $\mathrm{C} 10$, finite element approach $1585 \mathrm{kNm}(12.8 \%$ lower than conventional approach). Under column C10, finite element computes $2410 \mathrm{kNm}$ which is $17 \%$ lower than conventional approach. Overall finite element approach computes its bending moment in Y direction which is lower generally in range of $6.2 \%$ to $21.4 \%$.

A typical stress contour of raft for loose soil using finite element approach is shown in Figure 7.

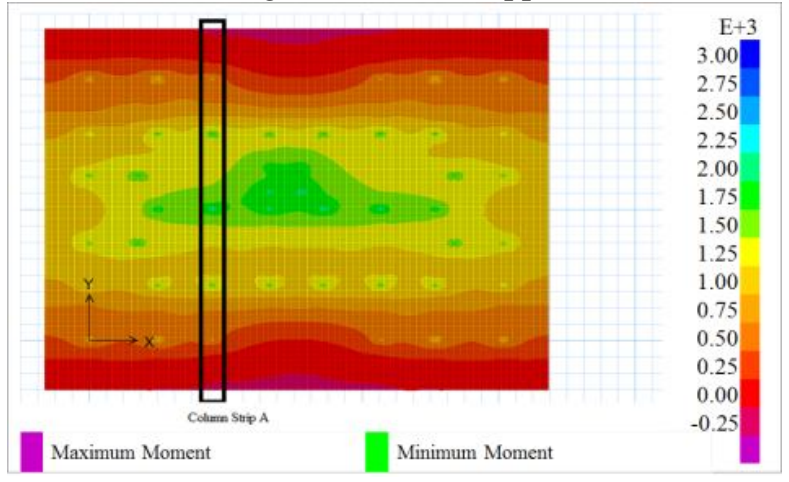

Figure 7.Contour diagram of moment in Y direction for loose soil

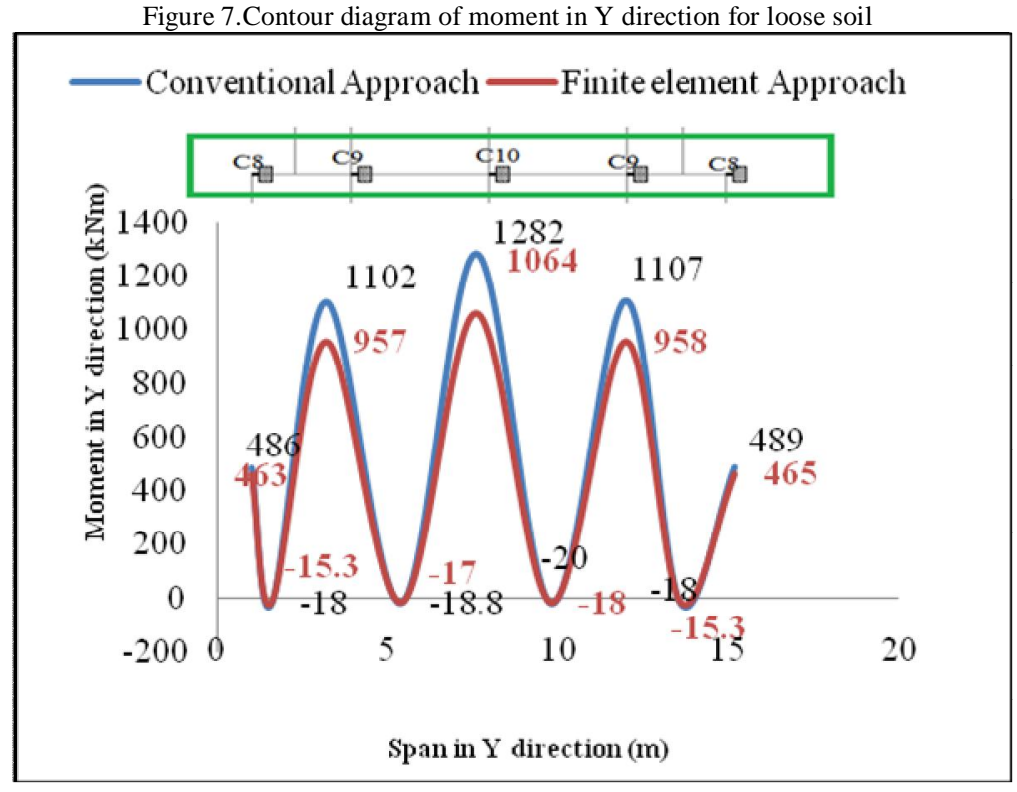

Graph 6.Variation of Moment in Y direction (column strip A) for medium soil.

Graph 6 shows variation of moment in Y direction for medium soil along column strip A (Refer Figure 2).As per conventional approach, at column C8 a sagging bending moment of $486 \mathrm{kNm}$. In between column C8 and C9, 
bending moment decrease from 486kNm (sagging) to $18 \mathrm{kNm}$ (hogging), this further increase and become 1102 $\mathrm{kNm}$ (sagging) under column C9. Further bending moment decreases $1102 \mathrm{kNm}$ (sagging) to $18.8 \mathrm{kNm}$ (hogging) at in between C9 and C10.Then the bending moment increase from $18.8 \mathrm{kNm}$ (hogging) to $1282 \mathrm{kNm}$ (sagging) at under column C10. Same trend of bending moment is presented for the remaining half of the column strip. It is observed that sagging bending moment is present at column location and hogging bending moment is present at middle panel.

Variation of bending moment for the same strip (column strip A), it studied by finite element approach. It is observed that bending moment obtained by finite element approach is lesser as conventional approach. The finite element approach gives $15.3 \mathrm{kNm}$ between of $\mathrm{C} 8$ and $\mathrm{C} 9$ which is lower by $17.6 \%$ in comparison with conventional approach. Under column C9; bending moment obtained by finite element approach is lower by $15.1 \%$ in comparison with conventional approach. At center of $\mathrm{C} 9$ and $\mathrm{C} 10$, finite element approach $17 \mathrm{kNm}(10.5 \%$ lower than conventional approach). Under column C10, finite element approach is lower by $20 \%$ in comparison with conventional approach. Overall finite element approach computes its bending moment in Y direction which is lower generally in range of $10 \%$ to $17.6 \%$.

Between edge and first intermediate column it is observed that a tension zone is developed indicating raft leaving contact with the sub soil. Also at the center of column strip tension zone is observed. However, the intensity of tension developed at the center of the raft is of lower intensity in comparison with the tension zone developed near the periphery. A typical stress contour of raft for medium soil using finite element approach is shown in Figure 8.

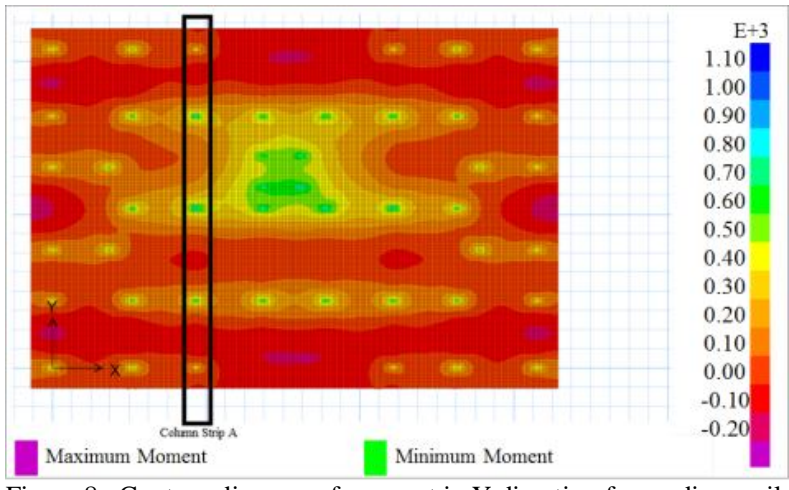

Figure 8. Contour diagram of moment in $\mathrm{Y}$ direction for medium soil.

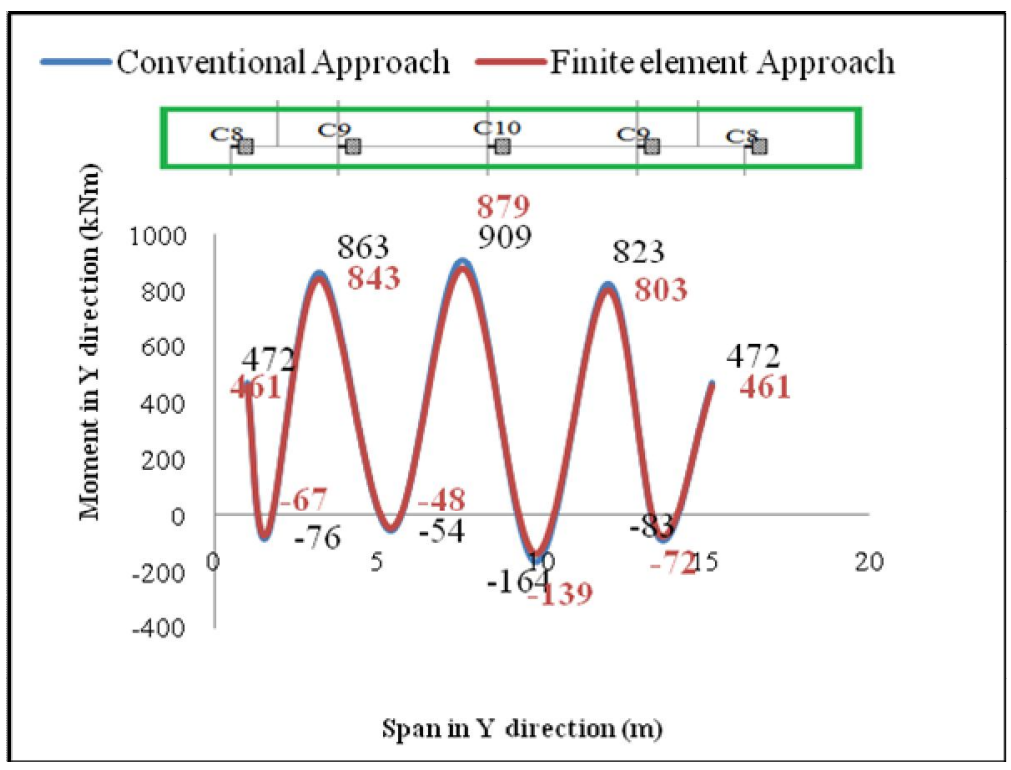

Graph 7.Variation of Moment in Y direction (column strip A) for hard soil. 
Graph 7 shows variation of moment in $\mathrm{Y}$ direction for hard soil along column strip A (Refer Figure 2). As per conventional approach, at column C8, a sagging bending moment of $472 \mathrm{kNm}$. In between column C8 and C9, bending moment decrease from $472 \mathrm{kNm}$ (sagging) to $76 \mathrm{kNm}$ (hogging), this further increase and become 863 $\mathrm{kNm}$ (sagging) under column C9. Further bending moment decreases $863 \mathrm{kNm}$ (sagging) to $54 \mathrm{kNm}$ (hogging) at in between C9and C10.Then the bending moment increase from 54kNm (hogging) to $909 \mathrm{kNm}$ (sagging) at under column C10. The bending moment decrease to a minimum hogging $164 \mathrm{kNm}$ at a center of strip C. Same trend of bending moment is presented for the remaining half of the column strip. It is observed that sagging bending moment is present at column location and hogging bending moment is present at middle panel.

Variation of bending moment for the same strip (column strip A), it studied by finite element approach. It is observed that bending moment obtained by finite element approach is lesser as compared to conventional approach. The finite element approach gives $67 \mathrm{kNm}$ between of $\mathrm{C} 8$ and $\mathrm{C} 9$ which is $13.4 \%$ in comparison with conventional approach. Under column C9; bending moment obtained by finite element approach is lower by $2.3 \%$ in comparison with conventional approach. At center of $\mathrm{C} 9$ and $\mathrm{C} 10$, finite element approach $48 \mathrm{kNm}(12.5 \%$ lower than conventional approach). Under column $\mathrm{C} 10$, finite element approach is lower by $3.4 \%$ in comparison with conventional approach. Overall finite element approach computes its bending moment in $\mathrm{Y}$ direction which is lower generally in range of $2.3 \%$ to $13.4 \%$.

Between edge and first intermediate column it is observed that a tension zone is developed indicating raft leaving contact with the sub soil. Also, at the center of column strip tension zone is observed. However the intensity of tension developed at the center of the raft is higher intensity in comparison with medium soil.

Considering the variation of bending moment in Y direction for all type of soil, same trend is observed for all type of soil .It is observed that, in case of loose soil the bending moment remains sagging in nature over entire column strip. With increasing stiffness of soil, tension zone are getting developed. As the stiffness of the soil increases it is observed that as one travels from edge towards center, the intensity of bending moment in tension zone increase. As well the extent of influence of tension zone increases. A typical stress contour of raft for hard soil using finite element approach is shown in Figure 9.

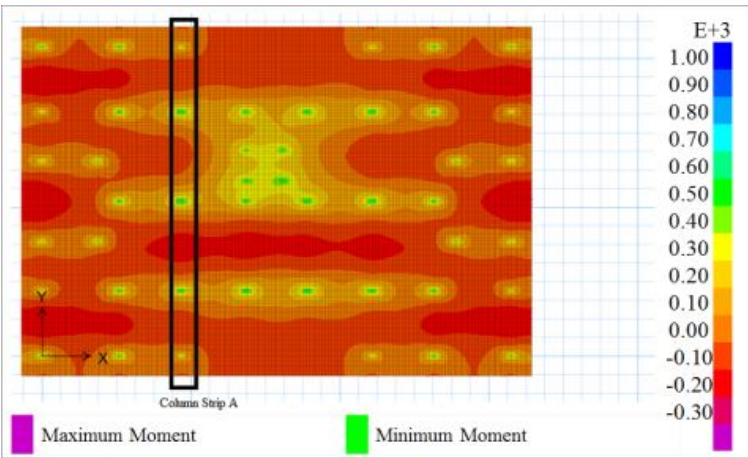

Figure 9. Contour diagram of moment in Y direction for hard soil. 


\section{Soil Pressure (Column strip B)}

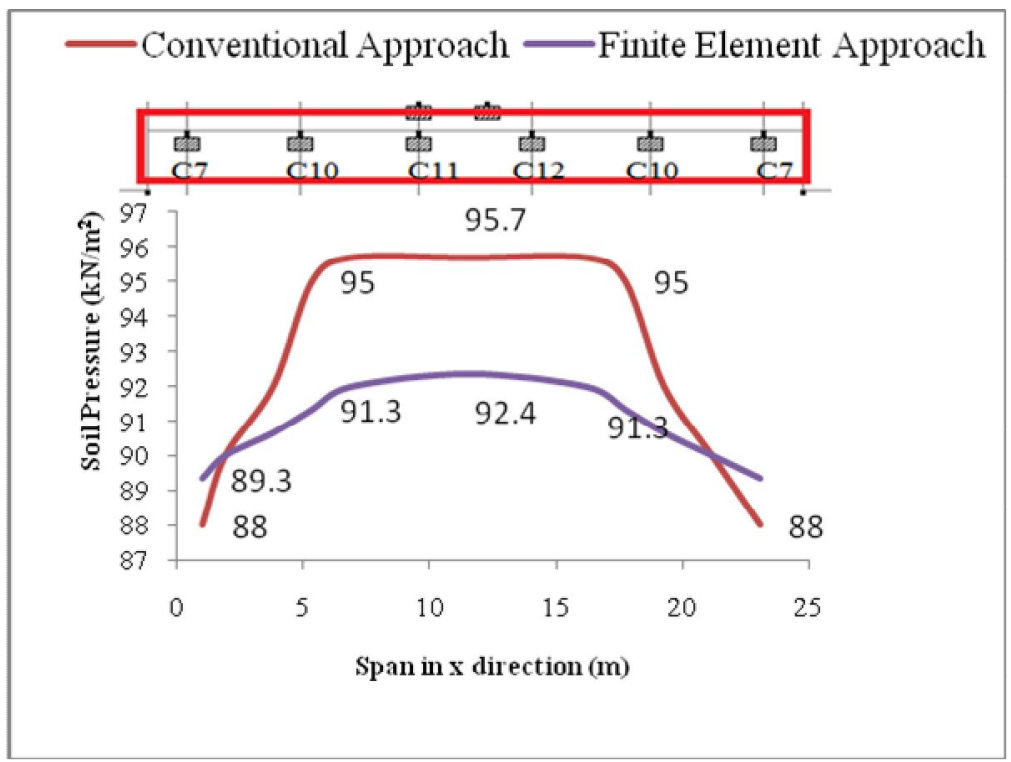

Graph 8.Variation of soil pressure in X direction (column strip B) for loose soil.

Graph 8 shows variation of soil pressure in X direction for loose soil along column strip B (Refer Figure 2). As per conventional approach, near edge soil pressure is as low as $88 \mathrm{kN} / \mathrm{m}^{2}$ which further increase steeply to $95 \mathrm{kN} / \mathrm{m}^{2}$ beneath column C7. There afterwards it is nearly constant up to the center of column strip. Same trend is observed on other side also. In between column C7and C10, soli pressure increases from $88 \mathrm{kN} / \mathrm{m}^{2}$ to $95 \mathrm{kN} / \mathrm{m}^{2}$. By finite element method the same trend is observed .However as we travel towards center the rate of increase of soil pressure is becoming milder. It is observed that soil pressure obtained finite element methods are very much lower especially in central portion of column strip in comparison with conventional method.

Variation of soil pressure for the same strip (column strip B), is also studied by finite element approach. It is observed that soil pressure obtained by finite element approach is lesser as compared to conventional approach. The finite element approach gives $89.3 \mathrm{kN} / \mathrm{m}^{2}$ at center of $\mathrm{C} 7$ which is more by $1.47 \%$ in comparison of conventional approach. Under column C10, soil pressure obtained by finite element approach is lower by $4 \%$ in comparison of conventional approach. Overall finite element approach computes soil pressure in $\mathrm{X}$ direction which is lower generally in range of $1.47 \%$ to $4 \%$.

A typical stress contour of raft for loose soil using finite element approach is shown in Figure 10.

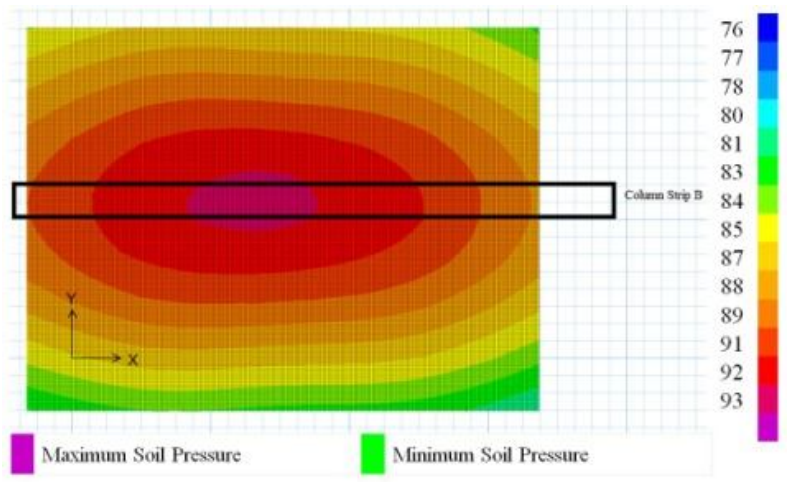

Figure 10. Contour Diagram of soil pressure for loose soil. 


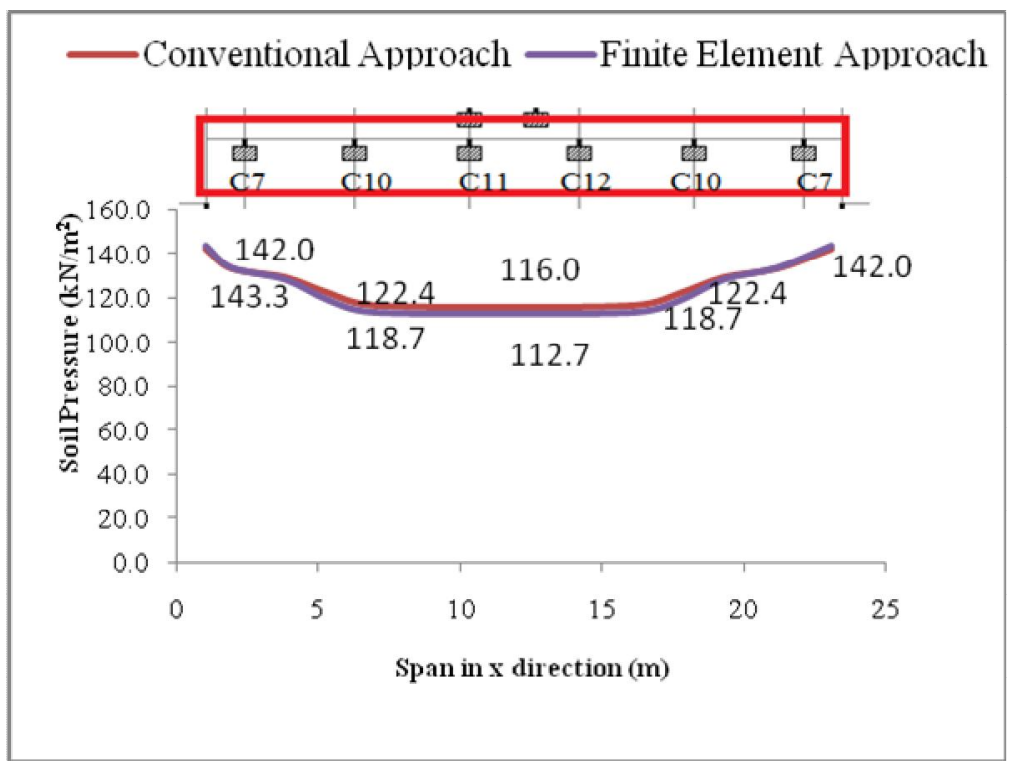

Graph 10.Variation of soil pressure in X direction (column strip B) for medium soil.

Graph 10 shows variation of soil pressure in X direction for medium soil along column strip B (Refer Figure 2).With soil becoming soil pressure distribution beneath the strip is tending towards uniformity. However now the pressure near the edge is highest and decreases as we proceed toward center. In the central portion the soil pressure is found to be nearly uniform. It is observed that soil pressure obtained finite element methods are very much lower in comparison with conventional method.

Variation of soil pressure for the same strip (column strip B), is also studied by finite element approach. The finite element approach gives $142 \mathrm{kN} / \mathrm{m}^{2}$ at center of $\mathrm{C} 7$ which is $0.91 \%$ more than conventional approach. Under column $\mathrm{C} 10$, soil pressure obtained by finite element approach is $3.1 \%$ more than conventional approach. Overall finite element approach computes soil pressure in X direction which is generally in range of $0.91 \%$ to $3.1 \%$. A typical stress contour of raft for medium soil using finite element approach is shown in Figure 11.

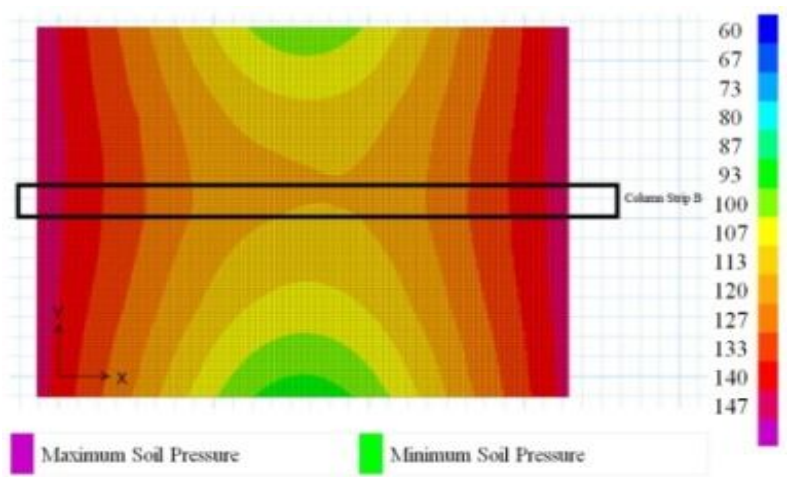

Figure 11. Contour Diagram of soil pressure for medium soil. 


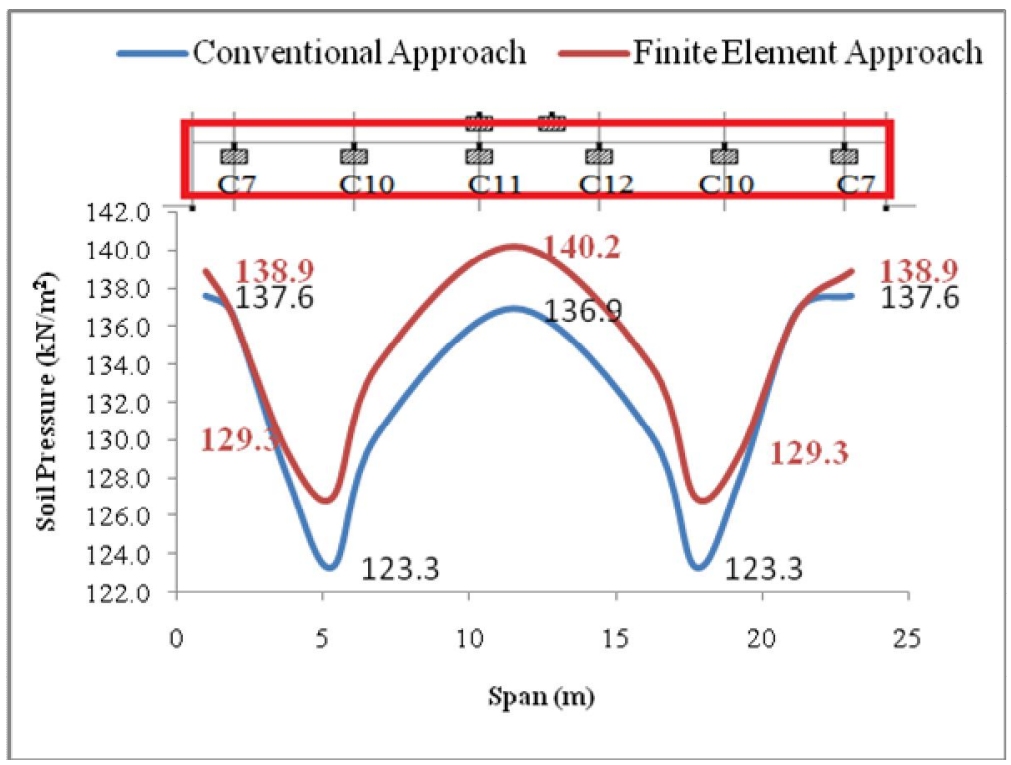

Graph 11.Variation of soil pressure in X direction (column strip B) for hard soil.

Graph 11 shows variation of soil pressure in X direction for hard soil along column strip B (Refer Figure 2). As per conventional approach, near edge soil pressure is as more as $137.6 \mathrm{kN} / \mathrm{m}^{2}$ which further decreases steeply to123.3 $\mathrm{kN} / \mathrm{m}^{2}$ beneath column C10. Then after words in between column C10 to C11 soil pressure suddenly increase from $123.3 \mathrm{kN} / \mathrm{m}^{2}$ to $136.9 \mathrm{kN} / \mathrm{m}^{2}$. Same trend is observed on other side also. By finite element method the same trend is observed. It is observed that soil pressure obtained finite element methods are very much lower in comparison with conventional approach.

Variation of soil pressure for the same strip (column strip B), is also studied by finite element approach. The finite element approach gives $138.9 \mathrm{kN} / \mathrm{m}^{2}$ at center of $\mathrm{C} 7$ which is $0.94 \%$ more than conventional approach. Under column $\mathrm{C} 10$ to $\mathrm{C} 12$, soil pressure obtained by finite element approach is $4.8 \%$ to $2.4 \%$ more than conventional approach. Overall finite element approach computes soil pressure in X direction which is generally in range of 0.94 $\%$ to $4.8 \%$. This revels that finite element approach computes soil pressure for every node and it is more accurate as compared to conventional approach. A typical stress contour of raft for hard soil using finite element approach is shown in Figure 12.

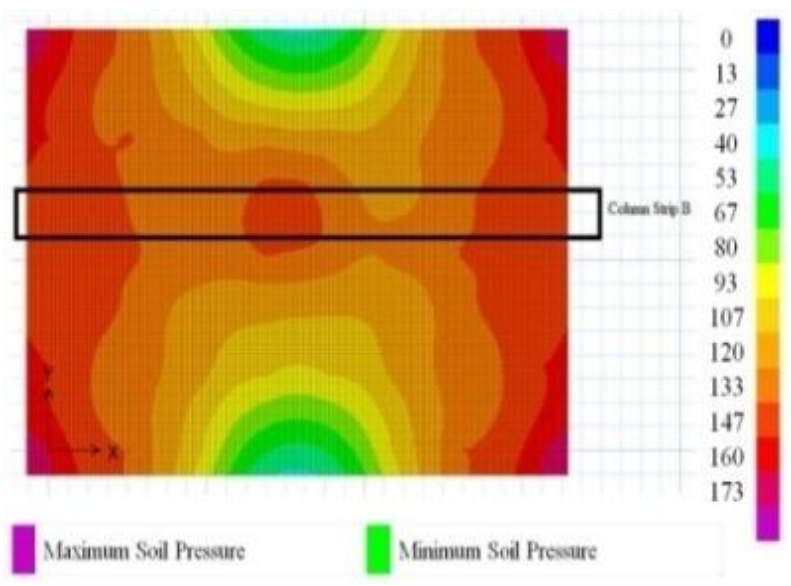

Figure 12.Contour Diagram of soil pressure for hard soil. 


\section{CONCLUSION}

From the present investigation following conclusion is drawn;

1. The results obtained from, conventional approach and finite element approach are of same nature and trend. However, finite element approach computes lesser bending moment in compression to conventional approach-in $\mathrm{X}$ and $\mathrm{Y}$ direction.

2. For loose soil bending moment is sagging in nature; over entire of raft. However, as soil stiffness increases tension zone is created. From the edge as we proceed toward centre the intensity and extent of tension zone goes increasing. However, the effect is more in $\mathrm{X}$ direction as compared to $\mathrm{Y}$ direction.

3. For loose soil, pressure distribution beneath the raft is lower at edge and goes on increasing towards the centre. In the central zone, in between column, it remains almost constant. For medium soil, at the edge, pressure distribution is high and goes on reducing towards the centre with very mild rate. For hard soil, pressure distribution at the edges is high, reduces under the edge columns and then after increases in the central part.

4. Overall it is observed that, the conventional approach overestimates the bending moment in $\mathrm{X}$ and $\mathrm{Y}$ direction for loose and medium soil. However, as stiffness of the soil increases the difference between conventional approach and finite element approach reduces and becomes almost negligible in case of hard soil. Therefore, finite element approach for loose and medium soil is recommended for getting more precise results.

\section{REFERENCES}

[1] Dr. Shihada, Dr.Hamad, "Modifications of Conventional Rigid and Flexible Methods for Mat Foundation Design", Islamic University of Gaza, Civil Engineering Department (August, 2008).

[2] Dr. Mohammad Al-Ansari, Haytham Adnan Sadeq, Mohammed SaleemTaha, "Structural Design of Raft Foundation", Qatar University college of engineering (01-01-2009).

[3] Mohamed SaadEldin, Arafa El-Helloty, "Effect of Opening on Behavior of Raft Foundations Resting on Different Types of Sand Soil", International Journal of Computer Applications Volume 94 - No.7 (May 2014).

[4] Dr.S.A.Halkude,M.G.Kalyanshetti,S.M.Barelikar,"Seismic Response of R.C. Frames with Raft Footing Considering Soil Structure Interaction",International Journal of Current Engineering and Technology Volume 4-No 3 (June 2014)

[5] Dr.S.S.Patil, M.G.Kalyanshetti, S.S.Dyawarkonda,"Parametric study of R.C frame with raft foundation considering soil structure interaction using spring",International Journal of science and Engineering Development Research Volume1 - Issue 4 (April 2016).

[6] I.S 2950 "Indian Standard Code of Practice for design and construction of raft foundations", Part 1: Design (Second Revision), Bureau of Indian Standards, New Delhi, 1981.

[7] IS 1893 Part I "Criteria for Earthquake Resistant Design of Structures-General Provisions and Buildings", Bureau of Indian Standards, New Delhi, 2002.

[8] A. S. Balasurbamaniam, C. Surarak, "Investigation of the Behavior of Piled Raft Foundations in Sand by Numerical Modeling", Griffith School of Engineering, Griffith University, Australia.

[9] M. Aoki, M. Maruoka, N. Sahasi, Y. Okamura, Y. Ikuta, "A Case History of Raft Foundation Behavior for a Large-Scaled Building Complex", Takenaka Corporation, Osaka Head Office, Osaka, Japan. (1993)

[10] G Srilakshmi, and Darshan Moudgalya N S, “Analysis of piled raft foundation using finite element method", International Journal of Engineering Research and science \& technology, Volumn 2 (August 2013)

[11] Akpila, S B, "Bearing Capacity and settlement response of raft foundation on sand using standard penetration test method", Department of Civil Engineering Rivers State University of Science and Technology.

[12] V. Garg and M.S. Hora, "Liner Soil structure interaction effect on column", Department of Civil Engineering (2012)

[13] C.M. Wang, Y.K. Chow, Y. C, "Analysis of rectangular thick plate resting on eleasic half space", National University of Singapore (25 Oct 2000)

[14] Youssef F. Rashed, “ Boundary Domain element method for analysis of building raft foundation” (13 April 2005)

[15] Sharatchandragupta, "Raft Foundation Design and Analysis with A Practical".

[16] P.C.Varghese, "Foundation Engineering", Textbook on Geotechnical engineering deal with soil mechanics and foundation engineering.

[17] Braja.M.Das, "Principle of Geotechnical Engineering", Principle of foundation engineering 